\title{
Effects of changes in practice of electroconvulsive therapy over a 2 year period
}

\author{
Kate Trezise and Bill Conlon
}

\begin{abstract}
The administration and outcome of electroconvultive thercpy (ECT) were studied retrospectively over two successtve periods of 12 months, betore and after replacement of our Ectron Series 5 ECT machine by a Thymation DGX. If was found that using the Thymation enabled the same outcome of ECT to be achleved, while actministering sionilicantty fower treatments per patient. Poselble explonations for this finding are discussed.
\end{abstract}

The Royal College of Psychiatrists has carried out two surveys of electroconvulstve therapy (ECT) practice in the UK (Pippard \& Ellam, 1981; Pippard, 1992). The authors demonstrated that psychiatric practice was below standard in twothirds of clinics surveyed, and failed to meet minimum guidelines in one out of ten clinics.

In particular. Pippard (1992) indicated that junior doctors were not always trained to give safe and effective ECT, and that one in four treatment applications either failed to produce an adequate seizure, or was not properly monitored. It was also found that the consultant with designated responsibility for ECT was very rarely present in over half the clinics reviewed. The role of personal supervision and training of junior doctors performing ECT by a consultant is considered to be of particular importance by the Royal College of Psychiatrists (1995).

In July 1994, our Ectron Series 5 ECT machine was replaced by a Thymatron DGx. The Series 5 has been recognised as underpowered (Royal College of Psychiatrists, 1995) with a maximum output of $400 \mathrm{mC}$, as compared with $1008 \mathrm{mC}$ for the Thymatron, and is no longer recommended for routine use. We had ourselves become concerned about the number of patients in whom we were unable to induce seizures of adequate therapeutic length when using the Series 5, and had therefore decided to upgrade our equipment in line with the recommendations of the College.

Introducing the new machine required increased consultant supervision of ECT sessions, and training of both medical and ancillary staff in its proper use. This prompted us to examine our standards of ECT practice, and we decided to study the effects of changing the ECT machine, and of consequently increased supervision of treatment sessions, on ECT administration and outcome.

\section{The study}

Retrospective analysis of case notes was performed for all patients receiving ECT during the year before, and the year after the changeover of ECT machine; 64 and 60 patients respectively. from a catchment area of 310000 . Information was gathered from the casenotes and from other sources as required, including discussion with colleagues, and records kept by the ECT clinic staff.

The following information was recorded for each patient: name; date of birth; gender; unit number; consultant; legal status during treatment: in-patient or out-patient status; diagnosis; number of treatments recetved; range of motor fit length; range of energy settings used; medication during treatment; and outcome. Full details were available for 62 patients treated with the Ectron Series 5 (Group 1), and all 60 patients treated with the Thymatron DGx (Group 2).

Diagnoses were ascertained from careful study of both in-patient notes and discharge summaries. They were divided into severe depressive disorder with or without psychotic symptoms; depressive disorder with an additional diagnosis (cerebrovascular disease, dementia, anxiety disorder, personality disorder, and schizophrenia); and diagnoses other than depression (schizophrenia, manic episode, schizo-affective disorder, mixed affective episode, and alcohol induced dementia).

Outcomes were defined as recovered, improved, or no change. (There were no patients who had been made worse by treatment.) These were determined at the completion of treatment by studying case notes and discharge summaries as before.

Medication was classified into major tranquillisers, tricyclic antidepressants (TCAs), selective 
serotonin reuptake inhibitors (SSRIs), other antidepressants, minor tranquillisers, lithium, carbamazepine, and any other drugs.

\section{Findings}

There was no significant difference (NS) between the groups in terms of gender, age, in-patient or out-patient status, or legal status during treatment (see Table 1).

There was no difference in diagnoses between the two groups. Three-quarters of patients in each group had a diagnosis of depressive disorder, and the proportions in the other two diagnostic categories were not significantly different (see Table 2).

The outcomes for the two groups were virtually identical. For both treatment groups $89 \%$ of patients were either recovered or improved, the remaining $11 \%$ being unchanged (Table 2 ).

The medication received by the patients during treatment was similar for the two groups, with the marked exception of antidepressants. Very similar proportions in each group were receiving antidepressant medication, but for patients in Group 1 the majority of these were TCAs, whereas for Group 2, a significantly greater proportion of patients were prescribed SSRIs $(P<0.001$, Table 2). There was no significant difference between the numbers in each group receiving any other type of medication.

The overall rate of complications for the first treatment group was $15 \%$ (six patients with confusion or persistent memory loss, and three who became hypomanic). The corresponding figure for the second group was 10\% (six patients with confusion or memory loss. See Table 3).

Of the group treated with the Ectron Series 5 , 12 patients (19\%) had persistently short fits. Of these patients, half were treated at the maximum energy setting of the machine. For the group of patients treated with the Thymatron, only one patient $(2 \%)$ had fits which were persistently short $(P<0.05$, Table 3). Unfortunately, however, this is not a strictly accurate comparison, as the method of timing the motor fits was altered slightly between the two groups.

The patients treated with the Thymatron received significantly fewer treatments per course of ECT. The mean (s.d.) number of treatments received by patients in Group 1 was 6.78 (2.47), and for the patients in Group 2, the corresponding figure was 5.58 (2.12), a difference of 1.2 treatments per course $(P<0.04$, Table 3$)$.

\section{Comments}

One limitation of the study was that because diagnoses were not operationally defined, it is not possible to be certain that the two groups were
Table 1. Demographic comparison of the two groups

\begin{tabular}{llll}
\hline & $\begin{array}{l}\text { Group I } \\
(\boldsymbol{n}-64)\end{array}$ & $\begin{array}{l}\text { Group 2 } \\
(\boldsymbol{n}-60)\end{array}$ & $P<\left(x^{2}\right)$ \\
\hline Female patients & $44(69 \%)$ & $40(67 \%)$ & NS \\
Mean age (years) & 59.8 & 61.4 & NS \\
In-patients & $55(86 \%)$ & $53(88 \%)$ & NS \\
Informal patients & $49(76 \%)$ & $48(80 \%)$ & NS \\
\hline
\end{tabular}

Table 2. Comparison of diagnosis and outcome between the two groups

\begin{tabular}{|c|c|c|c|}
\hline & $\begin{array}{l}\text { Group } 1 \\
(n=62) \\
(\%)\end{array}$ & $\begin{array}{l}\text { Group } 2 \\
(n=60) \\
(\%)\end{array}$ & $P<\left(x^{2}\right)$ \\
\hline $\begin{array}{l}\text { Diagnosis } \\
\text { Depression } \\
\text { Depression and } \\
\text { comorbid diagnosis } \\
\text { Other diagnosis }\end{array}$ & $\begin{array}{r}49(76) \\
8(13) \\
7(11)\end{array}$ & $\begin{array}{l}45(75) \\
13(22) \\
2(3)\end{array}$ & $\begin{array}{l}\text { NS } \\
\text { NS } \\
\text { NS }\end{array}$ \\
\hline $\begin{array}{l}\text { Outcome } \\
\text { Recovered } \\
\text { Improved } \\
\text { No change }\end{array}$ & $\begin{array}{c}36(58) \\
19(31) \\
7(11)\end{array}$ & $\begin{array}{c}34(57) \\
19(32) \\
7(11)\end{array}$ & $\begin{array}{l}\text { NS } \\
\text { NS } \\
\text { NS }\end{array}$ \\
\hline $\begin{array}{l}\text { Medication } \\
\text { TCAs } \\
\text { SSRIs }\end{array}$ & $\begin{array}{l}39(63) \\
13(21)\end{array}$ & $\begin{array}{l}19(32) \\
30(50)\end{array}$ & $\begin{array}{l}0.001 \\
0.001\end{array}$ \\
\hline
\end{tabular}

Table 3. Comparison of length of treatment and occurrence of complications

\begin{tabular}{|c|c|c|c|}
\hline & $\begin{array}{l}\text { Group } 1 \\
(n=62)\end{array}$ & $\begin{array}{l}\text { Group } 2 \\
(n=60)\end{array}$ & $\begin{array}{l}P<\left(x^{2}\right. \\
\text { except } \\
\text { "-teat) }\end{array}$ \\
\hline $\begin{array}{l}\text { Mean number of } \\
\text { treatments per } \\
\text { course (s.d.) }\end{array}$ & $6.78(2.47)$ & $5.58(2.12)$ & $0.004^{\circ}$ \\
\hline $\begin{array}{l}\text { Complications } \\
\text { Short fits }\end{array}$ & $\begin{array}{r}9(15 \%) \\
12(19 \%)\end{array}$ & $\begin{array}{l}6(10 \%) \\
1(2 \%)\end{array}$ & $\begin{array}{l}\text { NS } \\
0.05\end{array}$ \\
\hline
\end{tabular}

directly comparable in terms of severity of illness. Another confounding factor was that for a period of 11 weeks during the second half of the study. methohexitone sodium for induction of anaesthesia became unavailable. During this time propofol was used instead. Propofol has been observed to reduce fit length when used for ECT, and is therefore not recommended for this purpose (Royal College of Psychiatrists, 1995). Some reports, however, suggest that this shortening of fits is not accompanied by any reduction in therapeutic efficacy (Fear et al, 1993). For our patients, of whom nine were affected, outcome 
and average number of treatments received did not appear to differ significantly from the figures for the group as a whole.

The main finding of this study was that while using the Thymatron DGx in place of the Ectron Series 5, we were able to achieve the same results in terms of treatment outcome, while giving significantly fewer treatments per patient. There would appear to be several possible explanations for this.

Firstly it is possible that changes in antidepressant prescribing might have made a difference between the two groups of patients. It is known that both TCAs and SSRIs reduce fit threshold (Markowitz \& Brown, 1987; Feighner \& Boyer, 1991), but these effects are complex and probably vary even between members of each drug group (Royal College of Psychiatrists, 1995). It is therefore difficult to reach any conclusions about the effects of alterations in prescribing practice on our results.

Secondly the differences between the two groups might have been accounted for by changes in practice of one or more consultants. This does not appear to have been the case however, as seven out of eight consultants reduced the average number of treatments given by approximately one per course. It seems unlikely that they would have decided independently of one another to use fewer treatments during the course of the study, hence this explanation can probably be discounted.

Thirdly the Thymatron is a much more powerful machine, hence those patients who might not have convulsed adequately with the Ectron, for reasons of high fit threshold, could perhaps have been more effectively treated with the new machine. In support of this argument, 23 patients in the second group (38\%) were treated at energy settings which exceeded the maximum output of the Series 5 .

A final possible explanation for the marked difference in the numbers of treatments received by the two groups is the level of supervision of treatment sessions. For the Group 1 patients, a total of 97 treatment sessions were held over 12 months. Of these only five were attended by one of the supervising clinicians. Following introduction of the Thymatron, however, 91 of 97 sessions were supervised directly by one or both doctors with a special interest in ECT. We ensured that the technique of the junior doctors giving treatment was optimised, and adjusted the energy settings on the machine in accordance with the documented response to treatment.

\section{Conclusion}

It is not possible to determine which of these factors has had most impact on the improved efficiency of ECT noted during the study period. The Thymatron seems to have made it possible to treat a group of patients who previously might not have received adequate ECT, but it is unlikely that such a marked difference would have been apparent without supervision by experienced personnel to ensure that the machine was adjusted and used appropriately.

Following completion of this study, the EEG monitoring facility on the Thymatron DGx is now being used for all patients treated. It is hoped that this will help us further to improve the administration and monitoring of ECT, when coupled with an ongoing programme of staff education.

\section{Acknowledgement}

We wish to thank Dr Tariq Saraf for statistical advice and assistance.

\section{References}

Fear, C. F., LTtTenohns, C. S. \& Rouse, E. (1993) Propofol and ECT. British Journal of Psychiatry, 162, 421-422.

FEIGHNER, J. P. \& BOYER, W. F. (1991) Selective Serotonin Reuptake Inhibitors; The Clinical Use of Citalopram. Fluacetine, Fluvaxamine, Paraxetine and Sertraline. Chichester: John Wiley.

MARKOWTtz, J. C. \& BROWN, R. P. (1987) Selzures with neuroleptics and antidepressants. General Hospital Psychiatry, 9, 135-141.

PIPPARD, J. (1992) Audit of electroconvulstve treatment in two national health service regions. British Journal of Psychiatry, 160, 621-637.

- \& ELAM, L. (1981) Electroconvulstve treatment in Great Britain. British Journal of Psychiatry, 139, 563-568.

ROYAL COLLEGE OF PSYCHIATRISTS (1995) The ECT Handbook. CR39. London: RCPsych.

*Kate Trezise, Registrar in Psychiatry; and Bill Conlon, Consultant Psychiatrist and Clinical Tutor, Bushey Fields Hospital, Bushey Fields Road, Russells Hall, Dudley, West Midlands DY1 $2 L Z$

*Correspondence 